\title{
Could boron compounds be effective against SARS-CoV-2?
}

\author{
Ataseven $\mathrm{H}^{1}$, Sayin $\mathrm{K}^{2}$, Tüzün $\mathrm{B}^{3}$, Gedikli $\mathrm{MA}^{4}$ \\ Faculty of Medicine, Department of Gastroenterology, Sivas Cumhuriyet University, Sivas, Turkey. \\ krysayin@gmail.com
}

\begin{abstract}
BACKGROUND: Seven dioxaborole compounds are investigated in this study. Structural and spectral characterization is done at $M 062 X / 6-31+G(d, p)$ level in the water. Active sites of these compounds are determined using molecular electrostatic potential (MEP) maps. Electrophilic and nucleophilic attack regions are determined.

AIM: We aimed to determine whether Boron-Containing Compounds (BCCs) inhibitor used in the treatment of COVID-19 are effective against SARS Cov-2 in silico.

RESULTS AND CONCLUSION: Since SARS-CoV-2 is a worldwide health problem, anti-viral properties of studied boron-containing compounds were investigated by molecular docking calculations. In addition to these calculations, MM/PSBA calculations were performed. It was found that boron compounds can be good drug candidate against SARS-CoV-2 and the best compound is ((R)-1-((S)-3-(4-(aminomethyl)phenyl)-2benzamidopropanamido)-4-guanidinobutyl)boronic acid (C26) (Tab. 2, Fig. 6, Ref. 29). Text in PDF www.elis.sk KEY WORDS: boronate ester, dioxaborole, in silico, SARS-CoV-2, MD calculations.
\end{abstract}

\section{Introduction}

In December 2019, the novel coronavirus that first appeared in bats in Wuhan, Hubei province of China and is thought to be transmitted, with unknown intermediary animals, was named as novel coronavirus 2019 (2019-nCoV) or severe acute respiratory syndrome coronavirus 2 (SARS-CoV-2) and appeared as a pandemic threatening the world. The disease caused by SARSCoV-2 was named coronavirus disease-19 (COVID-19) (1). It has 7 strains in humans, including coronaviruses, 229E, NL63, OC43, HKU1, Middle East respiratory syndrome (MERS) -CoV, severe acute respiratory syndrome (SARS)-CoV, and 2019-novel coronavirus (nCoV) (2). Approximately 28 million 680 thousand COVID-19 cases and 917 thousand 500 deaths due to COVID-19 have been reported by the World Health Organization (WHO) to date (13/09/2020) (3). The incubation period in COVID-19 varies between 2 and 14 days, and it is transmitted by contact or respiration with infected droplets. Symptoms are usually fever, cough, fatigue, weakness and shortness of breath. While the disease is asymptomatic in most people, it is mild in some people and progresses to pneumonia, acute respiratory distress syndrome (ARDS) and multi-organ dysfunction in the elderly and patients with comor-

${ }^{1}$ Faculty of Medicine, Department of Gastroenterology, Sivas Cumhuriyet University, Sivas, Turkey, ${ }^{2}$ Faculty of Science, Department of Chemistry, Sivas Cumhuriyet University, Sivas, Turkey, ${ }^{3}$ Plantal and Animal Production Department, Sivas Technical Sciences Vocational School, Sivas Cumhuriyet University, Sivas, Turkey, and ${ }^{4}$ Faculty of Medicine, Department of Internal Medicine, Sivas Cumhuriyet University, Sivas, Turkey

Address for correspondence: K. Sayin, ${ }^{2}$ Faculty of Science, Department of Chemistry, Sivas Cumhuriyet University, Sivas, Turkey. bid diseases. The mortality rate is thought to vary between $2 \%$ and $3 \%$ (4-6). The most important structural proteins of coronaviruses are trimeric spike $(\mathrm{S})$ protein, nucleocapsid $(\mathrm{N})$ protein, membrane $(\mathrm{M})$ protein and envelope $(\mathrm{E})$ protein. Beta-Coronaviruses contain the hemagglutinin esterase (HE) glycoprotein, just like the influenza virus. This hemagglutinin esterase enzyme is found especially in the envelope of beta coronaviruses. Hemagglutinin esterase mediates reversible binding to $\mathrm{O}$-acetylated sialic acids and acts as enzyme that destroy both lectin and the receptor (7). Scientists are conducting many drug studies for the treatment of COVID-19 disease. It has been stated in the studies conducted to date that many drugs such as interferon-alpha, ribavirin, chloroquine phosphate, arbidol and favipiravir can be used for the treatment of COVID-19. However, no effective drug can be used to treat COVID-19 $(8,9)$. It has been shown in previous studies that compounds containing boronic acid and boron have anti-viral effects against various viruses. It has been stated in many studies that boron is a potent anti-viral agent. Nocentini A. et al. have shown in their studies that benzoxaborols are effective against Hepatitis $\mathrm{C}(\mathrm{HCV})$ virus. Dijana Saftić et al demonstrated the high anti-viral effects of orthocarborane conjugates against Human cytomegalovirus (HCMV), herpes simplex virus type 1 (HSV-1), encephalomyocarditis virus (EMCV), human parainfluenza virus type 3 (HPIV-3), vesicular stomatitis virus. They showed that. In another study, Zeynep Ustaoğlu et al. showed that sodium pentaborate pentahydrate in textiles reduced the growth of adenovirus type 5 and polyvirus type 1 by $60 \%(10-12)$. Two molecular structures are thought to be essential for boron compounds' anti-viral activity, as the synthesis of boronic acid modifications and structures similar to nucleotide structures. Boronic acid modifications have a molecular structure that is of interest to glycoprotein structures. Viruses en- 
$753-758$

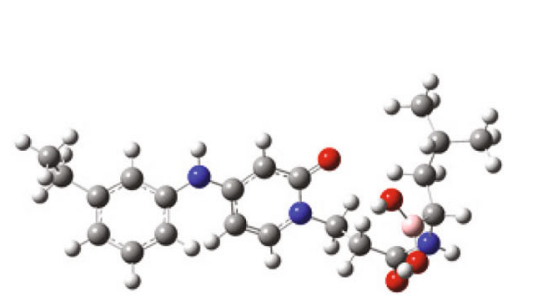

C1

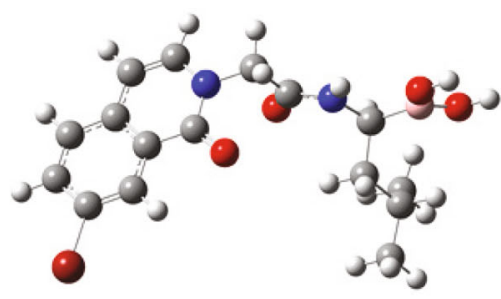

$\mathrm{C} 2$

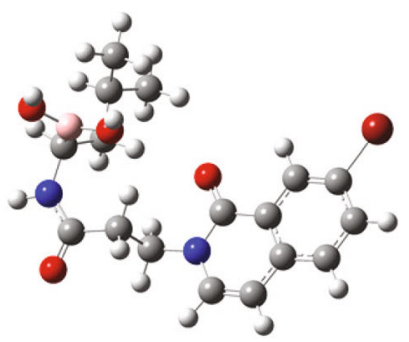

C3

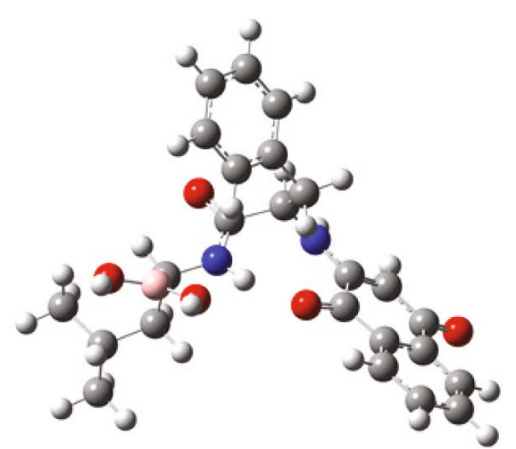

C4

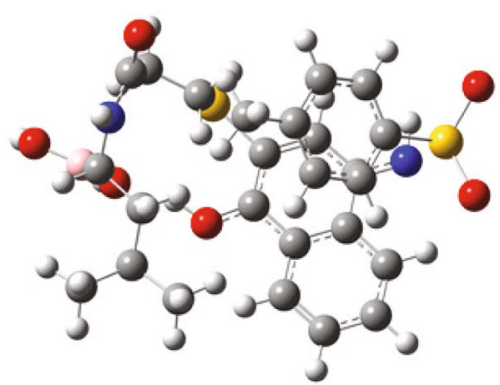

C5

Fig. 1. The optimized structures of boron compounds C1 - C5.

ter the cell by binding to the cell membrane. And this they make through the glycoproteins it carries on itself or the receptors on the host cell's membrane. If we block these glycoproteins or receptors with boronic acid, it cannot enter the host cell, it cannot reproduce. It is thought that boron molecules formed by the synthesis of similar nucleotide structures replace purines and pyrimidines used in genetic coding and inhibit reproduction genetically $(13,14)$. Boron containing compounds (BCCs) have broad application area such as optic, biological, anticancer, anti-viral, etc. It has been reported that medical drugs containing boron have toxicity. In the late 20 th century, it has been precisely reported that elemental boron and many BCC have low toxicity for human and animals. Researches on this subject have shown that the toxicity is not directly caused by boron (15). Many researches and preclinic test are still being performed for this aim (15). In this study, sixty-three boron-containing compounds are analyzed as an anti-viral agent against SARS-CoV-2 by in silico technique. Furthermore, molecular mechanics energies combined with the Poisson-Boltzmann surface area (MM/ PBSA) analysis is performed.

Initially, the whole compounds are optimized at B3LYP-D3/6-31+G(d,p) level in the water. Then, these compounds are minimized by OPLS_3e method for the ligand preparation stage. In the second stage of molecular docking analyses, target proteins which are $6 \mathrm{M} 0 \mathrm{~J}$ (16), 5RF1, and 7BV2 (17) are minimized with the same method. $6 \mathrm{X} 6 \mathrm{P}, 5 \mathrm{RF} 1$, and 7BV2 proteins are spike glycoprotein, main protease, and RNA dependent RNA polymerase of SARS-CoV-2 virus, respectively. After minimizations, site map or ligand-binding domains (LBDs) of target proteins are calculated. Especially, receptor-binding domains (RBD) are selected from LBDs and defined for calculations. Molecular docking calculations are performed, and compounds that could be effective in the treatment of

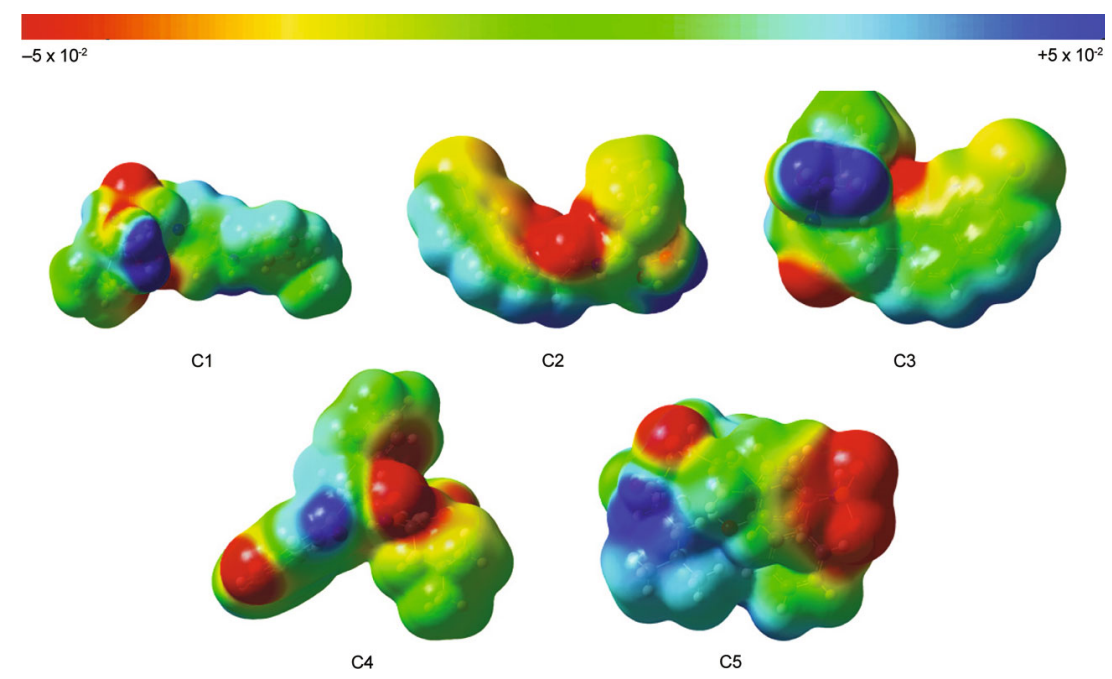

Fig. 2. The MEP maps of studied BCCs, C1 - C5. 
Tab. 1. Molecular docking results of selected BCCs against target proteins.

\begin{tabular}{lllllll}
\hline Compounds & $\mathrm{DS}^{\mathrm{a}}$ & $\mathrm{LE}^{\mathrm{a}}$ & $\mathrm{E}_{\mathrm{vdw}}{ }^{\mathrm{a}}$ & $\mathrm{E}_{\text {Coul }}{ }^{\mathrm{a}}$ & $\mathrm{E}_{\text {Int }}{ }^{\mathrm{a}}$ & $\mathrm{E}_{\mathrm{HBond}}{ }^{\mathrm{a}}$ \\
\hline 5RF1 & & & & & & \\
C59 & -8.87 & -0.22 & -38.30 & -26.20 & -64.51 & -2.74 \\
C26 & -7.42 & -0.22 & -22.49 & -21.71 & -44.20 & -3.06 \\
C11 & -7.04 & -0.17 & -34.53 & -13.39 & -47.91 & -2.52 \\
C48 & -6.42 & -0.26 & -30.45 & -8.03 & -38.48 & -1.71 \\
\hline 6M0J & & & & & & \\
C26 & -6.71 & -0.20 & -24.49 & -11.94 & -36.43 & -3.20 \\
C59 & -6.32 & -0.15 & -27.74 & -15.61 & -43.36 & -2.50 \\
C51 & -6.09 & -0.29 & -22.25 & -11.73 & -33.99 & -2.43 \\
\hline 7BV2 & & & & & & \\
C26 & -8.34 & -0.25 & -36.67 & -33.85 & -70.52 & -3.05 \\
C27 & -7.22 & -0.18 & -43.20 & -27.43 & -70.63 & -2.43 \\
C50 & -7.06 & -0.31 & -27.90 & -9.61 & -37.51 & -4.44 \\
C57 & -6.64 & -0.13 & -50.71 & -18.38 & -69.09 & -2.14 \\
C12 & -6.61 & -0.15 & -46.97 & -17.28 & -64.25 & -2.58 \\
C17 & -6.37 & -0.46 & -15.54 & -23.32 & -38.86 & -3.48 \\
C56 & -6.15 & -0.26 & -32.05 & -14.76 & -46.81 & -2.60 \\
C25 & -6.10 & -0.22 & -39.57 & -8.72 & -48.29 & -2.64 \\
\hline
\end{tabular}

a in $\mathrm{kcal} / \mathrm{mol}$

COVID19 are predicted. Finally, the MM/PBSA calculations are performed, and the most stable drug candidate in the interaction with target protein is determined in detail.

\section{Methods}

In silico analyses of BCCs compounds were done using four softwares, Gaussian, Maestro, Visual Molecular Dynamics and Nanoscale Molecular Dynamics (18-25). Initially, selected com- pounds are optimized at B3LYP-D3 method with $6-31+\mathrm{G}(\mathrm{d}, \mathrm{p})$ level in the water. To take into account the solute-solvent interactions, the polarizable continuum model (PCM) using the integral equation formalism variant (IEF-PCM) was used. These optimization calculations were done only to obtain ground-state structures. These calculations were performed using the Gaussian program.

In silico studies, molecular docking calculations were done using the Maestro 19.4 program. In this step, LigPrep, Protein Preparation, SiteMap, Receptor Grid Generation, Ligand Docking and Ligand Interaction modules were used. Studied compounds were re-minimized by OPLS3e method at $\mathrm{pH}=7 \pm 2$. 6M0J (16), 5RF1, and 7BV2 (17) were prepared, and site maps were calculated. LBDs were calculated by using SiteMap module. Receptor binding domains (RBD) were defined using the Receptor Grid Generation module. Molecular docking calculations between studied boron compounds and target proteins were performed.

In the last step, molecular mechanics energies combined with the Poisson-Boltzmann or generalized Born and surface area (MM/ PBSA) were done for each ligand-protein interaction by NAMD and VMD software $(24,25)$. In every five ns, Gibbs binding energy, van der Walls energy, kinetic energy and potential energy were calculated.
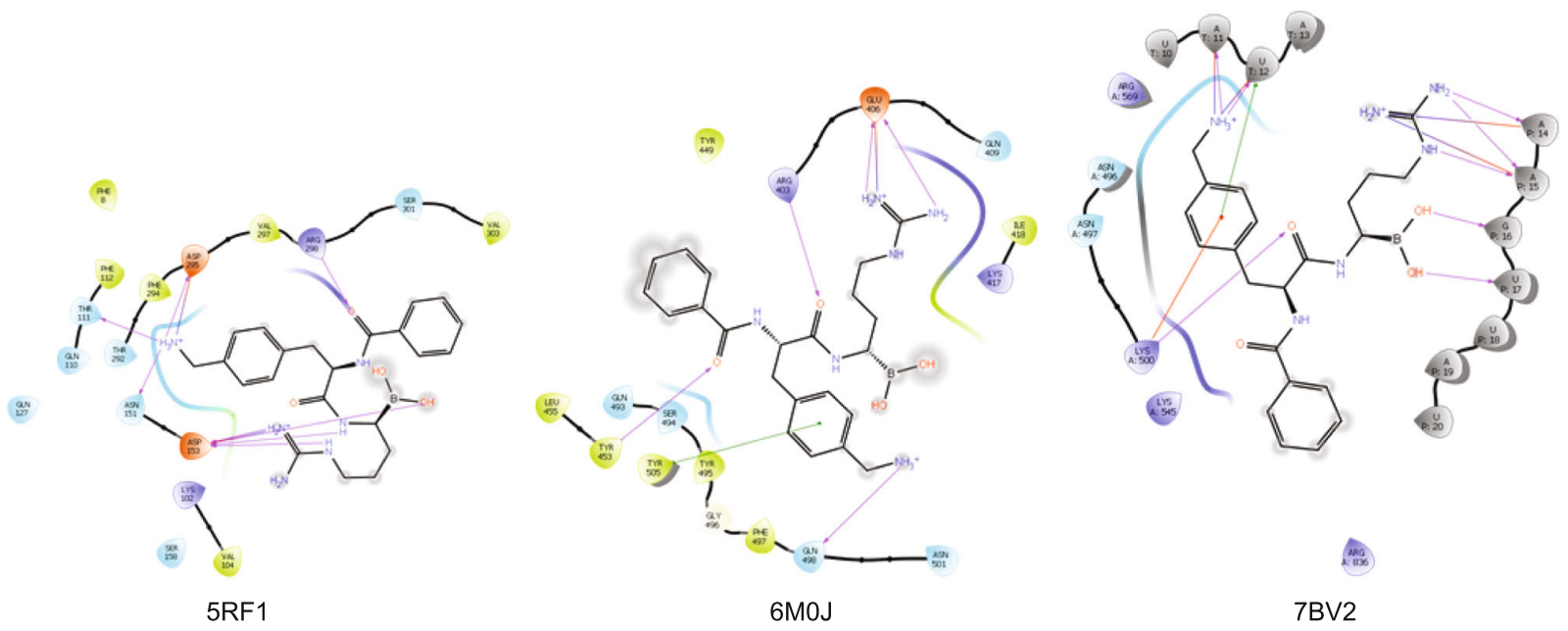

Charged (negative)
Charged (positive)
Glycine
Hydrophobic
Metal
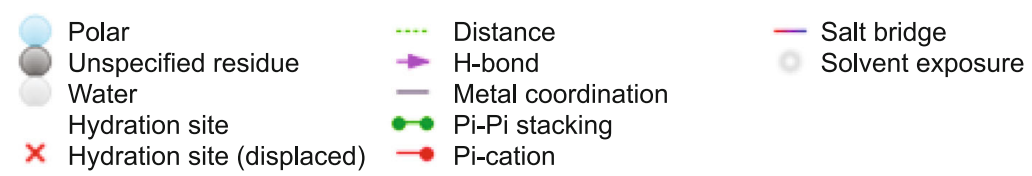

Fig. 3. The interaction schematic structures of $\mathrm{C} 26$ with the target proteins. 


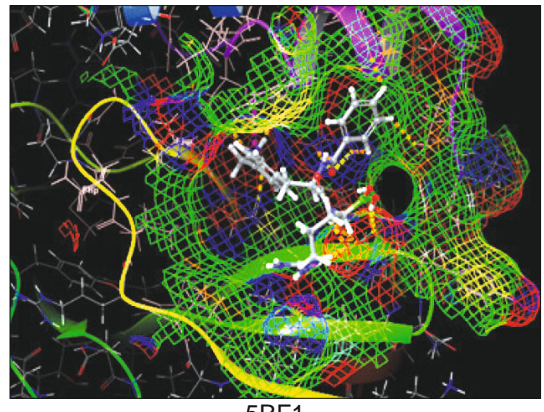

5RF1

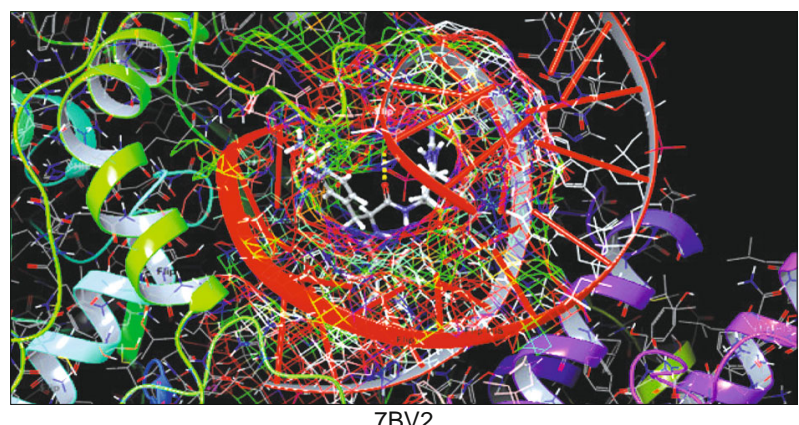

7BV2

Fig. 4. The SED diagram of target proteins.

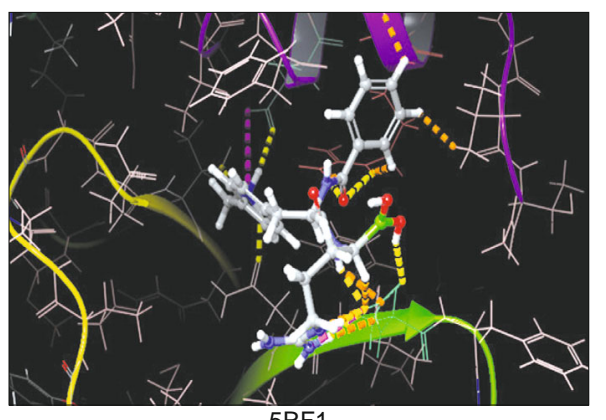

5RF1

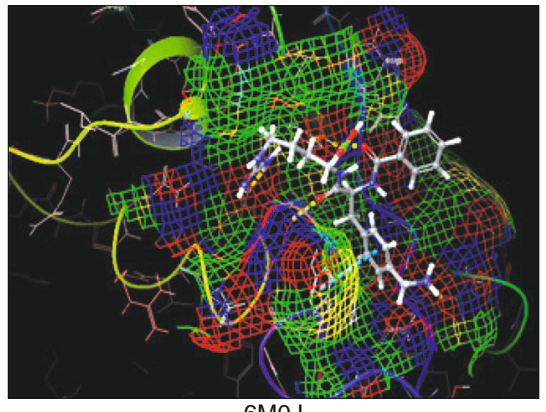

$6 \mathrm{MOJ}$

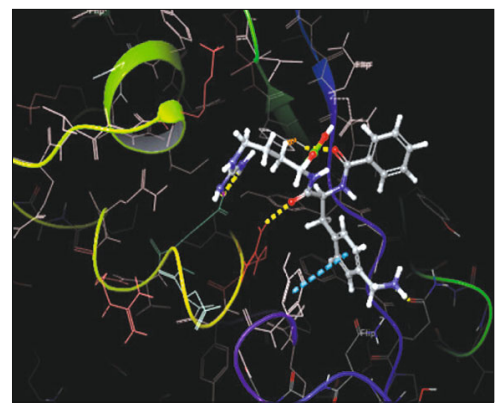

$6 \mathrm{MOJ}$

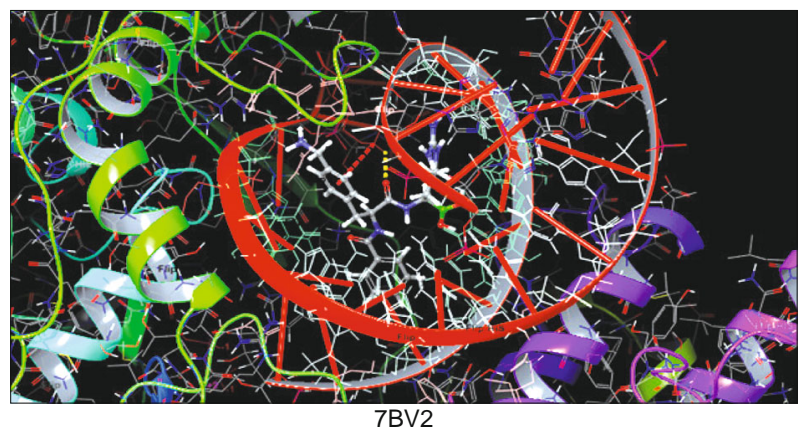

Fig. 5. Molecular docking structure between $\mathrm{C} 26$ and the target protein.

The optimization results show that the whole compounds are at the ground state, and no imaginary frequency is obtained from the calculations. The electronic geometry of the environment of boron atom is mainly found as trigonal and tetrahedral structures. The most important points are the determination of biological activity or druglikeness properties. Some papers claimed that BCCs are effective in the prevention of SARS-CoV-2. How these compounds affect SARS-CoV-2 is still a matter of problem. There is only one paper about this problem published by Çetiner et al. 2021 (26). Before the in silico investigations, the determination of active sites is significant for the prediction of effectivity. For this aim, a molecular electrostatic potential (MEP) map is calculated and examined in detail. Initially, MEP maps of C1 - C5 are represented in Figure 2. MEP maps of the other ones are represented in the supplemental material.

According to Figure 2, there is a colour scale above the MEP maps. The red colour implies the highest electron density region while blue one implies the lowest electron density region (27). In MEP map, red colour is mainly localized on the environment of the heteroatoms. Additionally, green colour is mainly localized on the nitrogen atoms due to the steric hurdle. These diagrams give an important clue which is about how the compounds interact with the target protein (28). Finally, oxygen may play an important role in the inhibitor-protein interaction. However, it is certain that it will contribute to the interaction with other atoms.

As for the other analyses, in silico analyses are done in detail. Molecular docking and MM-PBSA calculations are done. Initially, all ligands are prepared at $\mathrm{pH}=7 \pm$ 2 using OPLS3e method. Then, three proteins which are spike glycoprotein (PDB ID: 6M0J), RNA dependent RNA polymerase (PDB ID: 7BV2) and main protease (PDB ID: 5RF1) are minimized at the same level of theory. These three proteins are important for the SARS-CoV-2 virus. The effectivity of studied BCCs is investigated against

\section{Results and discussions}

Sixty-three boron compounds were optimized at B3LYP-D3/6$31+\mathrm{G}(\mathrm{d}, \mathrm{p})$ in water, and optimized structures of C1-C5 are represented in Figure 1. Additionally, optimized structures of the remaining compounds are represented in the supplemental material. these proteins. Molecular docking calculations were performed. Nearly the whole studied compounds are inhibiting the target protein. Molecular docking results of studied BCCs docking scores of which are lower than $-6 \mathrm{kcal} / \mathrm{mol}$ are given in Table 1 . Docking score (DS), ligand efficiency (LE), van der Walls energy $\left(\mathrm{E}_{\mathrm{vdw}}\right)$, coulomb energy $\left(\mathrm{E}_{\mathrm{Coul}}\right)$, interaction energy $\left(\mathrm{E}_{\mathrm{Int}}\right)$ and $\mathrm{H}$ bond en- 
Tab. 2. The MM-PBSA results for compound C26.

\begin{tabular}{|c|c|c|c|c|c|c|}
\hline \multirow{2}{*}{$\begin{array}{l}\text { Time } \\
\text { (ns) }\end{array}$} & \multicolumn{2}{|c|}{ 5RF1 } & \multicolumn{2}{|c|}{$6 \mathrm{MJ0}$} & \multicolumn{2}{|c|}{ 7BV2 } \\
\hline & $\mathrm{E}_{\text {Binding }}{ }^{\mathrm{a}}$ & SD & $\mathrm{E}_{\text {Binding }}{ }^{\mathrm{a}}$ & SD & $\mathrm{E}_{\text {Binding }}{ }^{\mathrm{a}}$ & SD \\
\hline 0 & -2782.0 & - & -2732.2 & - & -3097.0 & - \\
\hline 5 & -1859.6 & \pm 237.6 & -2615.4 & \pm 114.9 & -3056.0 & \pm 232.4 \\
\hline 10 & -2169.1 & \pm 254.1 & -2515.1 & \pm 89.2 & -3028.8 & \pm 329.8 \\
\hline 15 & -1928.2 & \pm 119.4 & -2439.1 & \pm 95.3 & -3225.3 & \pm 266.1 \\
\hline 20 & -2432.4 & \pm 198.4 & -2162.5 & \pm 161.8 & -2995.9 & \pm 201.5 \\
\hline 25 & -1699.7 & \pm 318.0 & -2361.2 & \pm 80.2 & -3146.8 & \pm 290.0 \\
\hline 30 & -1973.2 & \pm 238.0 & -2803.1 & \pm 289.3 & -2875.3 & \pm 229.5 \\
\hline 35 & -1927.0 & \pm 145.1 & -2413.4 & \pm 169.4 & -2990.6 & \pm 344.4 \\
\hline 40 & -2340.5 & \pm 154.3 & -2416.0 & \pm 107.6 & -2438.1 & \pm 246.0 \\
\hline 45 & -2296.4 & \pm 147.6 & -2348.9 & \pm 152.4 & -3098.5 & \pm 413.2 \\
\hline 50 & -1979.5 & \pm 201.7 & -2705.6 & \pm 116.6 & -2274.8 & \pm 328.5 \\
\hline 55 & -2075.1 & \pm 273.1 & -2790.4 & \pm 172.6 & -2607.7 & \pm 344.6 \\
\hline 60 & -2108.8 & \pm 89.2 & -2760.2 & \pm 119.4 & -3924.2 & \pm 397.7 \\
\hline 65 & -1751.8 & \pm 203.0 & -2321.4 & \pm 195.7 & -3258.9 & \pm 363.3 \\
\hline 70 & -2373.6 & \pm 207.3 & -2626.2 & \pm 245.4 & -3431.4 & \pm 201.4 \\
\hline 75 & -2322.6 & \pm 173.6 & -2616.2 & \pm 103.6 & -2899.9 & \pm 299.8 \\
\hline 80 & -1978.0 & \pm 101.0 & -2538.0 & \pm 91.1 & -3168.9 & \pm 330.6 \\
\hline 85 & -2430.7 & \pm 159.4 & -2750.7 & \pm 112.3 & -3903.8 & \pm 370.6 \\
\hline 90 & -2342.2 & \pm 198.9 & -3063.1 & \pm 213.2 & -3569.4 & \pm 251.6 \\
\hline 95 & -2252.6 & \pm 255.4 & -2605.6 & \pm 125.1 & -2871.1 & \pm 234.8 \\
\hline 100 & -1817.7 & \pm 146.3 & -2976.0 & \pm 189.9 & -3132.1 & \pm 313.3 \\
\hline
\end{tabular}

binding energy of ligand (8). The van der Walls energy is related with chemical interaction while Coulomb energy is related with physical interactions. The interaction energy is a sum of van der Walls and coulomb energy. This parameter is as important as docking score is, because, interaction energy shows that ligand can inhibit the protein or not. The last parameters is $\mathrm{H}$ Bond energy which occurred in ligand-protein interaction. The two studied compounds wich stand out in this project are $\mathrm{C} 26$ and C59. However, C59 inhibits the main protease and spike glycoproteins while C26 inhibits the all target proteins in this study. The interaction schematic structures of C26 are represented in Figure 3.

According to Figure 3, the dominant interaction types are hydrogen bond, polar, hydrophobic, charged (negative), pi-cation and solvent exposure $(29,30)$. However, the most striking one is hydrogen bond due to the fact that $\mathrm{H}$-bonding potential of $\mathrm{C} 26$ is

ergy $\left(\mathrm{E}_{\mathrm{HB} \text { ond }}\right)$ are reported in the same table. Molecular docking results of All compounds are given in Supp. Table S1 for 5RF1, $6 \mathrm{M} 0 \mathrm{~J}$ and 7BV2, respectively.

According to the docking results, nearly all studied BCCs interacted with target proteins. However, inhibitors to be focused on are selected according to their docking scores. Compounds with a docking score of less than $-6 \mathrm{kcal} / \mathrm{mol}$ are taken into consideration. According to Table 1, studied BCCs are active against three main targets of SARS-CoV-2. However, it can be said that the compounds studied are effective on RdRp and main protease but not on spike glycoprotein, according to others. The first parameter is docking score which is related with key-lock compatibility (29). This is the first wanted property due to the fact that ligand should be inserted in the ligand-binding domain of target protein. As for the ligand efficiency, this parameter is related with docking score and atom with nonhydrogen. The other three parameters are van der Walls, Coulomb and interaction energy. They are related with

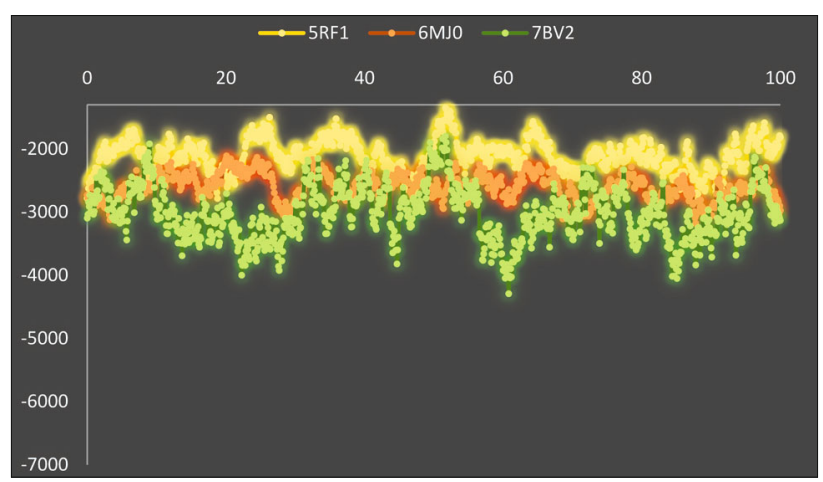

Fig. 6. The Gibbs binding energy in the range of $0-100 \mathrm{~ns}$. high. The surface electron distribution (SED) of the active site of proteins interacting with the ligand is shown in Figure 4.

According to Figure 4, there are three main colours, red, green and blue. The red one implies the highest electron density region, while the blue one shows the poorest electron density sites. Generally, H-bond occurs between inhibitor and red region of receptor binding site. Finally, the docking structures are represented in Figure 5 for C26.

The final investigation is Molecular Mechanics-PoissonBoltzmann Surface Area (MM-PSBA) calculation. Whether the target protein can be inhibited by ligand or not can be predicted from molecular docking calculations. These calculations cannot give the stability of interactions. However, this stability can be analyzed by MM-PSBA calculations. In this study, the stability is investigated in each 5 nanosecond (ns) in the range of 0-100 ns. The binding energy is calculated in each $5 \mathrm{~ns}$ for the all proteinligand complexes. Additionally, standard deviation is calculated, too. The results of MM-PSBA which are binding energy $\left(\mathrm{E}_{\text {Binding }}\right)$ and standard deviation (SD) analyses, are given in Table 2.

According to Table 2 and Figure 6, it can be said that, studied BCCs are effective against SARS-CoV-2. It can be said that C26 is effective against spike glycoprotein, RNA dependent RNA polymerase and main protease of SARS-CoV-2.

\section{Conclusions}

Boron containing compounds attract the attention of researcher. Especially, many of papers indicate that the BCCs have biological activity. In this study, the 63 compounds are examined against SARS-CoV-2. Initially, these compounds are optimized at B3LYP$\mathrm{D} 3 / 6-31+\mathrm{G}(\mathrm{d}, \mathrm{p})$ level in the water. Then, molecular docking analyses are performed against spike glycoprotein, main protease and 
$753-758$

RNA dependent RNA polymerase of SARS-CoV-2. Additionally, molecular mechanics-poisson-boltzmann surface area calculation is performed for selected interaction. In the view of all results, ((R)1-((S)-3-(4-(aminomethyl)phenyl)-2-benzamidopropanamido)4-guanidinobutyl)boronic acid is found as the best drug candidate for the treatment of COVID19.

\section{Acknowledgements}

The numerical calculations reported in this paper were fully/ partially performed at TUBITAK ULAKBIM, High Performance and Grid Computing Center (TRUBA resources). This work is supported by the Scientific Research Project Fund of Sivas Cumhuriyet University under project number RGD-020.

\section{References}

1. Singhal T. A review of coronavirus disease-2019 (COVID-19). Indian J Pediatr 2020; 87 (4): 281-286.

2. Paules CI, Marston HD, Fauci AS. Coronavirus infections - more than just the common cold. JAMA 2020; 323 (8): 707-708.

3. WHO. WHO Coronavirus Disease (COVID-19) Dashboard 2020.

4. Novel CPERE. The epidemiological characteristics of an outbreak of 2019 novel coronavirus diseases (COVID-19) in China. Zhonghua liu xing bing xue za zhi 2020; 41 (2): 145.

5. Team CCR, Team CCR, Team CCR, Bialek S, Boundy E, Bowen V et al. Severe outcomes among patients with coronavirus disease 2019 (COVID-19) - United States, February 12 - March 16, 2020. Morbidity Mortality Weekly Report 2020; 69 (12): 343-346.

6. Aktaş A, Sener K, Yılmaz N, Tunç M, Yolcu S. Is Mean Platelet Volume Useful for Predicting the Prognosis of COVID-19 Diagnosed Patients? Age 54 (18, 191): 18, 191.

7. Tortorici MA, Walls AC, Lang Y, Wang C, Li Z, Koerhuis D et al. Structural basis for human coronavirus attachment to sialic acid receptors. Nature Struct Mol Biol 2019; 26 (6): 481-489.

8. Aktaş A, Tüzün B, Aslan R, Sayin K, Ataseven H. New anti-viral drugs for the treatment of COVID-19 instead of favipiravir. J Biomol Struct Dynam 2020: 1-11.

9. Dong L, Hu S, Gao J. Discovering drugs to treat coronavirus disease 2019 (COVID-19). Drug Discov Ther 2020; 14 (1): 58-60.

10. Nocentini A, Supuran CT, Winum JY. Benzoxaborole compounds for therapeutic uses: a patent review (2010-2018). Expert Opinion Ther Patents 2018; 28 (6): 493-504.

11. Saftić D, Studzińska M, Paradowska E, Piantanida I, Baranović G, Bialek-Pietras M et al. Comparative study of the effects of ortho-, meta-and para-carboranes (C2B10H12) on the physicochemical properties, cytotoxicity and antiviral activity of uridine and 2'-deoxyuridine boron cluster conjugates. Bioorganic Chem 2020; 94: 103466.

12. Iyigundogdu ZU, Demir O, Asutay AB, Sahin F. Developing novel antimicrobial and antiviral textile products. Appl Biochem Biotechnol 2017; 181 (3): 1155-1166.
13. Wang W, Yin R, Zhang M, Yu R, Hao C, Zhang L1, et al. Boronic acid modifications enhance the anti-influenza A virus activities of novel quindoline derivatives. J Med Chem 2017; 60 (7): 2840-2852.

14. Tikhonov S, Vovna V. Photoelectron spectra and electronic structure of boron dipropyl imidoylamidinates. J Struct Chem 2015; 56 (3): 446-453.

15. Farfán-García E, Castillo-Mendieta N, Ciprés-Flores F, PadillaMartínez I, Trujillo-Ferrara J, Soriano-Ursúa M. Current data regarding the structure-toxicity relationship of boron-containing compounds. Toxicol Lett 2016; 258: 115-125.

16. Lan J, Ge J, Yu J, Shan S, Zhou H, Fan S et al. Structure of the SARS-CoV-2 spike receptor-binding domain bound to the ACE2 receptor. Nature 2020; 581 (7807): 215-220.

17. Yin W, Mao C, Luan X, Shen DD, Shen Q, Su H et al. Structural basis for inhibition of the RNA-dependent RNA polymerase from SARSCoV-2 by remdesivir. Science 2020; 368 (6498): 1499-1504.

18. Frisch M, Trucks G, Schlegel H, Scuseria G, Robb M, Cheeseman J et al. Gaussian 09, Revision D. 01, 2009, Gaussian. Inc, Wallingford CT. 2009.

19. Dennington II R, Keith T, Millam J. GaussView 5.0, Wallingford, CT. 2009.

20. Release S. 3: Maestro, Schrödinger, LLC: New York, NY, USA, 2019. 2019.

21. Schrödinger L. Schrödinger Release 2019-4: LigPrep. New York, NY: Schrödinger, LLC. 2019.

22. Friesner RA, Murphy RB, Repasky MP, Frye LL, Greenwood JR, Halgren TA, et al. Extra precision glide: Docking and scoring incorporating a model of hydrophobic enclosure for protein- ligand complexes. J Med Chem 2006; 49 (21): 6177-6196.

23. Friesner RA, Banks JL, Murphy RB, Halgren TA, Klicic JJ, Mainz DT et al. Glide: a new approach for rapid, accurate docking and scoring. 1. Method and assessment of docking accuracy. J Med Chem 2004; 47 (7): 1739-1749.

24. Humphrey W, Dalke A, Schulten K. VMD: visual molecular dynamics. J Mol Graphics 1996; 14 (1): 33-38.

25. Nelson MT, Humphrey W, Gursoy A, Dalke A, Kalé LV, Skeel RD et al. NAMD: a parallel, object-oriented molecular dynamics program. Internat J Supercomp Appl High Perform Comp 1996; 10 (4): 251-268.

26. Cetiner E, Sayin K, Tuzun B, Ataseven H. Could boron-containing compounds (BCCs) be effective against SARS-CoV-2 as anti-viral agent? Bratisl Med J 2021; 122 (4): 263-269.

27. Tüzün B. Examination of anti-oxidant properties and molecular docking parameters of some compounds in human body. Turk Comp Theor Chem 4 (2): 76-87.

28. Tüzün B, Sayin K. Investigations over optical properties of boron complexes of benzothiazolines. Spectrochimica Acta Part A: Mol Biomol Spectroscopy 2019; 208: 48-56.

29. Aktas A, Tuzun B, Taskin A, Sayin K, Ataseven H. How do arbidol and its analogs inhibit the SARS-CoV-2? Bratisl Med J 2020; 121 (10): 705-711.

Received March 23, 2021. Accepted April 24, 2021. 